\title{
Erratum to: Measurement of platelet reactivity of patients with cardiovascular disease on-treatment with acetyl salicylic acid: a prospective study
}

\author{
Abdalla Awidi · Akram Saleh • Manar Dweik • \\ Baraah Kailani · Mohammed Abu-Fara • \\ Rinad Nabulsi • Abdulbari Bener
}

Published online: 5 July 2011

(c) Springer 2011

Erratum to: Heart Vessels

DOI 10.1007/s00380-010-0086-0

Unfortunately, the column titles of Table 3 appeared incorrectly in the article cited above.

Table 3 should be correctly shown as follows:

Table 3 Platelet aggregation studies in the two study groups

\begin{tabular}{llc}
\hline & $\begin{array}{l}\text { ASA alone } \\
(n=179) n(\%)\end{array}$ & $\begin{array}{l}\text { ASA + clopidogrel } \\
(n=103) n(\%)\end{array}$ \\
\hline Resistant & $52(29.1)$ & $21(20.4)$ \\
Partially resistant & $36(20.1)$ & $9(8.7)$ \\
Sensitive & $91(50.8)$ & $73(70.9)$ \\
\hline
\end{tabular}

The online version of the original article can be found under doi:10.1007/s00380-010-0086-0.

A. Awidi · A. Saleh $\cdot$ M. Abu-Fara $\cdot$ R. Nabulsi

Department of Medicine, University of Jordan, Amman, Jordan

A. Awidi $(\bowtie) \cdot$ M. Dweik · B. Kailani

Thrombosis Hemostasis Laboratory, Jordan University Hospital,

Queen Rania Al Abdallah Street, Amman, Jordan

e-mail: aawidi@yahoo.com

A. Bener

Department of Medical Statistics and Epidemiology,

Hamad Medical Corporation,

Hamad General Hospital, Doha, Qatar

A. Bener

Department of Public Health and Medical Education,

Weill Cornell Medical College, New York, USA 